\title{
Connecting and making coherent teachers' knowledge: Building a knowledge-oriented culture
}

\author{
Linda C. LANGFORD \\ PHD Student \\ Charles Sturt University, Wagga Wagga NSW \\ Information Literacy Teacher \\ The King's School, Sydney, \\ NSW Australia
}

This paper is partly based on a doctoral thesis entitled Knowledge creation, knowledge sharing and knowledge use: A case study. The paper challenges teacher librarians to view themselves as knowledge architects in the designing and sustaining of a teachers' learning community - one which values teachers' knowledge as core business in the school. This paper builds a case for teacher librarians to realign their role by focusing on their colleagues' knowledge and asking: "How can teachers' knowledge be shared, and captured and disseminated to better enable a knowledge-oriented culture?"' and "What are the structures and processes that bring teachers' knowledge out into the open to be shared?" Part A of this paper presents a synopsis of the study's purpose, rationale and key issues. It brings together the theories of learning community and knowledge management in establishing a discourse that is centred on valuing, connecting and making coherent teachers' knowledge as essential in enabling a knowledge-oriented culture to grow and to flourish. Part B presents an overview of the study with a focus on one of its three themes: knowledge sharing. Part $C$ concludes with a brief discussion on how this research can contribute to the role of school libraries and teacher librarians in the emerging discourse on professional learning and knowledge sharing within and across work place units. 
Knowledge reservoirs in organisations are not static pools, but wellsprings constantly replenished with streams of new ideas and constituting an ever-flowing source of corporate renewal.

D. Leonard-Barton 1995: 3. 


\section{PART A Knowledge-oriented culture - sustaining the knowledge reservoir}

\section{Learning community and knowledge management: Underpinning theories}

Conceptually, learning community and knowledge management theories underpin this research into how teachers' create, share and use their knowledge. It is assumed that a learning community (see Appendix one) views its members' knowledge as not only an asset, but as core business, a driver in developing new ideas and an investment in its future. Its focus on knowledge processes and production guarantees that knowledge is continually being added and removed from the community through ensuring that, across the work units, a strategically organised knowledge management infrastructure is in place (Fullan 1999; Wiig 1993). Thus, a learning community has a knowledge-oriented culture: knowledge being simply viewed as the knowing how and the knowing why of things. A vibrant knowledge management infrastructure recognizes that personal knowledge is influenced by an individual's attitudes, experiences, beliefs and values through interactions with information. Such an infrastructure considers knowledge in the light of two aspects - tacit knowledge and explicit knowledge and provides structures and processes that bring its' members' knowledge out into the open.

For this study, it is convenient to use Prusak's definition of tacit knowledge as "a human asset buried in the minds of the individuals" (Molholm 2003: online); knowledge that is buried and thus more difficult to write down, and hence the reliance on people to bring this knowledge out into the open through discussion, stories and personal interaction. Explicit knowledge is tightly bound to tacit knowledge. For this study, it is viewed as the knowledge that can be more readily expressed in words or numbers, and can be shared through discussion or by writing it down and putting it into, for example, documents, procedures or databases. It is at this stage that a person's explicit knowledge becomes information for the receiver. In this study, information is viewed as explicit knowledge that has been codified in some form or more simply put, "Knowledge is what $I$ know and information is what we know" (Foskett 1982: 1). Knowledge creation then is a process that relies on the interaction of a person's knowledge with information, that is, the processing of information through, for example, personal experiences, beliefs, insights, hunches, attitudes, and emotions. Thus knowledge sharing is the explication and dissemination of these ideas through strategies that convert tacit knowledge to explicit knowledge - getting highly personal knowledge out into the open - for people to use (Gurteen 1999: online). Using knowledge involves processes of disseminating and diffusing existing 
knowledge, leading to some type of action. Knowledge use is simply stated as the process of using knowledge to initiate action (Sinclair \& Hardie 2000: online).

In this study, it was assumed that if structures and processes were organised that connected and made coherent the knowledge that teachers' create and share, then organisational knowledge, the collective knowing of a group, would be captured, made accessible to all members of the teachers' learning community, and used across teachers' work units. It was assumed that this would ensure that the right expertise got to the right person at the right time - a prime objective of a knowledge-oriented culture and an essential goal of school libraries.

\section{Rationale for the study}

As noted previously, teachers' learning communities are defined as knowledge-oriented cultures where shared vision, trust, team learning, personal mastery, flexibility to shift mental models and systems thinking work together to build a culture focussed on creating, sharing and using its teachers' knowledge to enrich the school's organisational knowledge (Senge 1990; Fullan 1999; Santosus 2001). It follows that teachers' knowledge is valued (Hargreaves 1999) and that the work place is characterised by an infrastructure that ensures teachers' knowledge is made coherent across the work units. This connecting and making coherent the knowledge that informs teachers' practice, the knowledge that comes from being immersed in their practice and the self reflective knowledge that comes from experimenting, trialling, observing and discussion would result in many positive outcomes. For instance:

- corporate amnesia, resulting from teachers who take what they know with them when they leave the school, is reduced despite natural movement of teachers (Davenport \& Prusak 1998),

- myopic communities (non-systems thinking) would give way to knowledge-oriented communities,

- the anorexic community, that is, one which is not productive and not developing its organisational capacity, would give way to a healthy community that truly is continually developing its capacity, and challenging the way its members work while actively creating the future (Sbarcea 2000), and

- leadership (transformative, invitational and shared) would be distributed across the system (Stoll \& Fink 1996).

There would be a focus on conversational communities where critical dialogue and conversation would be central processes in building the organisational knowledge of the learning community. Langford notes that:

Teachers need to talk to each other in groups, or one to one, and to have opportunities to receive or give help or simply converse about the meaning of change. ... If the vibrations along the school's (communication) web are to 
be in creative harmony then conversing at the most simplest level is necessary for the spread of mutual influence (1999: 208-9).

Langford believes that the strategic organising of structures that enable constructive and open dialogue and genuine feedback would facilitate the sharing of knowledge beyond teachers' individual work units, and would help to diffuse negative emotion and blocking of new ideas. If "conversation is the beginning of knowledge ... the full perfection of knowledge" (Wurman quoted in Langford 1999: 208), then opportunities to build a knowledge-oriented teachers' learning community will focus on teachers being with teachers - talking, sharing, reflecting, re-casting their ideas and having the confidence to trial new things (Louis \& Kruse 1995; Newmann \& Wehlage 1995; Sergiovanni 1994).

\section{Statement of the problem}

In general, teachers work mainly in isolation. Teachers often attend professional development activities by themselves, study in isolation, and when at their work place, are busy teaching, or supervising or coaching, therefore having little time to engage in critical debate, deeply discuss an idea or observe, trial, adapt or reflect on ideas. Teachers' tacit knowledge, that is, knowledge which is not easily visible and expressible, is "highly personal and hard to formalise ... [and] deeply rooted in an individual's action and experience ... ideals, values or emotions" (Nonaka \& Takeuchi 1995: 8), remains largely untapped. Thus it is not transformed into the learning community's explicit knowledge, the knowledge expressed in words and numbers and shared as hard data, and hence becomes inaccessible to all but the individual teacher (Fullan 1999; Stoll \& Fink 1996; Nonaka \& Takeuchi 1995). Thus, for this knowledge to become school wide, and embodied into products, services and systems, requires a knowledge-oriented infrastructure that actively nurtures teachers as they construct their knowledge through knowledge creation, knowledge sharing and knowledge utilisation experiences (Furlong 2001; Nonaka \& Takeuchi 1995).

In schools where teachers have had little opportunity to create, share and use their knowledge, teachers' knowledge becomes disjointed across their work units, contributing to significant gaps in the organisational knowledge of the school. Knowledge gaps are costly, unnecessary and contribute to fragmentation and incoherency in the school's organisational knowledge, which could have detrimental effects on the learning community (Furlong 2001). This is felt strongly when teachers, especially those who hold significant organisational knowledge in their heads, leave the work place (Fankhauser 1999; Todd 1999; see also Leonard-Barton 1995).

As well, and generally speaking, teachers have expressed confusion over mandated innovations that are never fully implemented, let alone critically examined, discussed, trialled and evaluated, and hence never institutionalised as best practice (Bryk et al 1998). Despite professional development support for teachers in their pursuit of deeper understanding of their knowledge-of-practice, knowledge-for-practice and knowledge-in-practice (Cochran-Smith \& Lytle 
1999), teachers continue to report that they feel a sense of disconnection to the purpose of the school. Their new ideas lay fallow, notwithstanding the richness of their experiences. In summary, if teachers have not had opportunities to share their knowledge then:

- personal and whole school knowledge reservoirs reduce (Leonard-Barton 1995);

- schools risk becoming stuck schools or those schools that seek freedom from outside demands and are not prepared to change (Rosenholtz 1989);

- funding for teachers’ professional learning is not accountable (Fullan 1999), and

- schools risk the investment in knowledge capital walking out the door (Davenport \& Prusak 1998; Svetvilas 2001).

Knowledge-oriented cultures act as deterrents against information fiefdoms (Todd 1999; Haeusler 2002) - Rosenthal's knowledge silos - and enable teachers across the various work units to feel confident about, and valued for, their knowledge. Schools as learning organisations, that is, those with knowledgeoriented cultures, are active in reducing the dilemma of isolated practice. Their teachers' learning communities seek to eliminate silos of expertise, or at least do a better job of having each silo interact with its neighbouring silos. Thus, this study assumes that good practices in knowledge creation, knowledge sharing and knowledge use dispense with isolated practices, generating a connected and coherence making knowledge-oriented culture, through unlocking the rich resources inside the minds of teachers. For example, in schools, teacher librarians, by dint of their position, are system thinkers. They have the capacity to understand the value of knowledge creation and knowledge sharing across work units by virtue of their cross-curricula positions. They inherently have the skills and knowledge to design and manage structures that build knowledge-oriented cultures yet many report that they are consistently frustrated in their attempts to collaborate with their colleagues, and to share their knowledge and to use their knowledge, such are the fissures that knowledge silos develop. Where knowledge silos (or information fiefdoms) are non-existent, then "knowledge will be able to more easily flow and find those who need it" (Rosenthal quoted in Denning 2002: online) and supposedly collaborative practice would thrive.

\section{Reflection}

Knowledge as core business in a teachers' learning community drives the developing and sustaining of a teachers' knowledge-oriented culture. For teacher librarians, learning community theory and knowledge management theory 
strongly inform teacher librarian practice. The lexicon of knowledge management coupled with the concept that school libraries are knowledge places where connection and action contend strongly with other library functions (Todd 2001) reminds us that we have a significant role in understanding how our teachers prefer to create, share and use their knowledge and thus, in understanding, move our school libraries towards a knowledge future where knowledge-of-practice, knowledge-for-practice and knowledge-in-practice (Cochran-Smith \& Lytle 1999) are dynamically replenishing the school's knowledge reservoir. 


\section{PART B Knowledge sharing - findings from a case study}

This research, an in-depth case study, was richly descriptive. It was informed by two dynamic concepts - learning communities and knowledge management. Specifically, it sought to identify the structures or processes that enabled a particular group of teachers to create, share and use their knowledge.

Part B of this paper addresses the outcomes, in brief, of one of the three themes within this study: knowledge sharing.

\section{Background}

The research was an in-depth case study of an Australian Catholic primary school teachers' learning community. The selection of the school was not based on its inclusion in a systemic environment but rather because it exhibited many of the features, as identified in the literature, of learning communities (see part A). In this study, a learning community, with its emphasis on knowledge as central to the generative and creative culture of a community, is viewed as having a knowledge-oriented culture. Knowledge as core asset, knowledge as core business, knowledge as investment and knowledge as driver are implied concepts in this study (Calvert et al 1994; Hargreaves 1999; Groundwater-Smith \& Sachs 2002).

The Principal of the school viewed the teachers' knowledge as an investment over time and that the need for continuous knowledge creation and knowledge-sharing activities drove the development of the various structures in which teachers could exchange ideas, talk, share, re-cast their ideas, trial new ideas and engage in some form of reflective practice. He saw his teachers as active contributors to the learning community.

\section{Research aims}

This qualitative research, based on a constructivist paradigm in which theory is grounded, was interpretive in nature in that it sought to identify how teachers' knowledge was created, shared and used. The principal research question was: How is knowledge created, shared and used in an Australian Catholic primary teachers' learning community? It specifically aimed to:

- identify structures that teachers preferred for creating, sharing and using their knowledge,

- identify processes that teachers preferred in creating, sharing and using their knowledge,

- establish what elements enabled teachers to engage in knowledge creating and sharing activities, and the application of new ideas, and 
- establish what elements were perceived as barriers to engaging in knowledge creating and sharing activities, and the application of new ideas.

\section{Participants}

Eighteen teachers (representing a cross section of teachers in the case study and comprising just under $50 \%$ of the core teachers within the selected school) participated in this study. They held undergraduate and/ or post-graduate qualifications in Education, of which $61 \%$ of them were actively pursing tertiary studies. A balance in gender was not an issue as the school was disproportionately female.

\section{Data collection}

Data were primarily collected through audio-recorded semi-structured interviews (45-60 minutes) in which each participant, after a pre-interview discussion clarifying the key concepts of this study, was encouraged to remember an incident of their choosing that they felt was critical to their professional learning. Participants were asked to reflect on their experience, that is, to tell their story through focussing on the processes and structures that enabled their participation and fostered their professional learning. As it was essential that the participant voices were not encumbered by researcher interference, this melded technique of critical incident and storytelling allowed the teachers' stories to unfold. As they recalled the events leading up to and including the chosen experience, emotions mingled with their memories. Stories weaved in and out of the three themes of knowledge creation, knowledge sharing and knowledge use, eliciting rich descriptive data.

A pilot study assisted in the clarification of the research question, culminating in a set of secondary questions that eventually became a framework for data analysis. The pilot study also aided in further refinement of the preinterview discussion, adjustments to prompting techniques, and honing of the researcher's interview skills.

Participant observation was the second method of data collection. Being employed by the school as a teacher librarian throughout the data collection period, and subsequent analysis of the data, allowed the researcher to observe how the structures and processes supported teachers in this learning community. It also gave her privileged information that enhanced interpretation of participant stories through understanding the nuances and the operating culture of the teachers' learning community. The researcher was aware of bias in interpretation and endeavoured to maintain a neutral stance when analysing the data. For instance, she recorded each interview to ensure that data analysed could be re-checked against the context in which it was delivered. She kept field notes, which guided her analysis, and also conducted post-interview discussions to clarify issues that were raised in the interviews, inviting each interviewee open access to their individual transcripts.

\section{Data analysis}


Data analysis occurred simultaneously with data collection. The constant comparison technique, which is well developed in grounded theory research, was trialled as a framework for analysing the transcripts of the pilot interviews (Lincoln \& Guba 1985; Patton 1990; Dey 1993; Williamson 2000). A simple matrix was subsequently developed based on the three main themes of this study. Each main theme was further divided into two sub-headings and these subheadings were further divided into two more sub-headings. This framework proved to be successful in allowing each piece of evidence, in the first instance, to be placed in several sub-headings and across themes. Qualitative analysis software (NVivo) assisted in concept mapping the various categories and their related data, and in coding like data across the three themes. The flexibility inherent in such a framework proved to be well suited to the nature of the concepts arising from the data (see Table 1).

Table 1 Example of hierarchical nature of categories

\begin{tabular}{|c|c|c|c|c|c|}
\hline $\begin{array}{l}\text { Level } 1 \\
\text { Themes }\end{array}$ & \multicolumn{2}{|c|}{$\begin{array}{c}\text { Level } 2 \\
\text { Organising strands }\end{array}$} & $\begin{array}{c}\text { Level } 3 \\
\text { Category A }\end{array}$ & $\begin{array}{c}\text { Level } 4 \\
\text { Category } \\
\text { Real life } \\
\text { indicator } 1\end{array}$ & $\begin{array}{c}\text { Level } 4 \\
\text { Category } \\
\text { Real life } \\
\text { indicator } 2\end{array}$ \\
\hline $\begin{array}{l}\text { Knowledge } \\
\text { creation }\end{array}$ & Process & Barrier & Perception & Motivation & $\begin{array}{l}\text { Mandated } \\
\text { new role }\end{array}$ \\
\hline $\begin{array}{c}\text { Knowledge } \\
\text { creation }\end{array}$ & Process & & Perception & Sustain & \\
\hline $\begin{array}{c}\text { Knowledge } \\
\text { creation }\end{array}$ & & Enabler & $\begin{array}{l}\text { Affective } \\
\text { response }\end{array}$ & $\begin{array}{l}\text { Confidence, } \\
\text { self esteem }\end{array}$ & $\begin{array}{l}\text { Credibility, } \\
\text { more } \\
\text { responsibilit } \\
y\end{array}$ \\
\hline $\begin{array}{c}\text { Knowledge } \\
\text { sharing }\end{array}$ & Structure & Enabler & $\begin{array}{l}\text { Affective } \\
\text { response }\end{array}$ & Confidence & Feedback \\
\hline
\end{tabular}

\section{Drawing theory from data}

The final analysis was set against a framework of four propositions (see Yin 1994 regarding case studies and connection to propositions), which assisted in re-examining the data to validate what was emerging as findings for each theme (see example Proposition 2 in conjunction with Table 2).

\section{Example Proposition 2}

A school has a knowledge-oriented culture if it develops strategic structures and processes for knowledge sharing, enabling teachers to explicate and disseminate their new ideas, through various modes of expression. 
The data that supported the theme knowledge sharing was reexamined for real life indicators that told of events, activities, experiences, feelings, and perceptions within the organising strands of structures or processes that linked evidence to support Proposition 2. If any evidence emerged that represented any one or combination of these structures or processes, they were subsequently grouped under the proposition and further analysed to reveal a possible finding.

Table 2 Knowledge sharing - evidence linking Proposition 2 to claims

\begin{tabular}{|l|l|l|l|}
\hline \multicolumn{1}{|c|}{$\begin{array}{c}\text { Proposition } \\
\text { structures }\end{array}$} & Strand & \multicolumn{1}{|c|}{ Real life indicators } & \multicolumn{1}{|c|}{ Probable claim } \\
\hline $\begin{array}{l}\text { Strategic } \\
\text { structures }\end{array}$ & $\begin{array}{l}\text { Professional learning } \\
\text { team, } \\
\text { Committees, } \\
\text { Teachers' shared drive. }\end{array}$ & $\begin{array}{l}\text { Teachers prefer to } \\
\text { share knowledge } \\
\text { together. }\end{array}$ \\
\hline $\begin{array}{l}\text { Explicate } \\
\text { ideas }\end{array}$ & Processes & $\begin{array}{l}\text { Plan together } \\
\text { Appreciative } \\
\text { behaviours }\end{array}$ & $\begin{array}{l}\text { Teachers prefer to } \\
\text { share knowledge } \\
\text { together. }\end{array}$ \\
\hline $\begin{array}{l}\text { Disseminate } \\
\text { ideas }\end{array}$ & Structures & $\begin{array}{l}\text { Ripple effect } \\
\text { Team observations } \\
\text { During work day }\end{array}$ & $\begin{array}{l}\text { Teachers prefer to use } \\
\text { structures that are } \\
\text { informal, small, high } \\
\text { trust, embedded into } \\
\text { work day }\end{array}$ \\
\hline $\begin{array}{l}\text { Various } \\
\text { modes }\end{array}$ & Processes & $\begin{array}{l}\text { Journaling } \\
\text { Writing papers } \\
\text { Trialing }\end{array}$ & $\begin{array}{l}\text { Teachers share } \\
\text { knowledge through } \\
\text { reflective practice }\end{array}$ \\
\hline $\begin{array}{l}\text { Various } \\
\text { modes }\end{array}$ & Structures & $\begin{array}{l}\text { Work time, lunch, } \\
\text { after work courses, } \\
\text { water cooler talk, } \\
\text { dinner meetings }\end{array}$ & $\begin{array}{l}\text { Teachers share their } \\
\text { knowledge in social } \\
\text { groups of their } \\
\text { choosing }\end{array}$ \\
\hline
\end{tabular}

\section{Knowledge sharing - the findings}

Sustainable knowledge sharing processes and structures convert highly personal knowledge into knowledge that can be expressed, or articulated, and then codified in some manner. These structures and processes are designed to enable people to get their highly personal knowledge out into the open and to be recast 
into useable knowledge that brings action such as decision-making or implementing of a new idea. However, as evidenced in this study, knowledge sharing is inherently tied to knowledge creation and hence structures and process that enable knowledge creation often enable knowledge sharing. Thus, at times throughout this study, it was difficult to separate knowledge creation from knowledge-sharing structures and processes. Therefore, it is acknowledged, in this study, that the phenomenon of knowledge sharing and knowledge creation is intrinsically tied, and thus, data will overlap. Words and phrases that embody ideas such as feedback, sharing, modelling, listening, reflection, credibility, group work, confidence, risk-taking, trust, understanding, communicating, connecting, coherence, and demonstrating were textual triggers that aided the separation of knowledge sharing data from knowledge creation data.

Bearing in mind the iterative nature of knowledge creation and knowledge sharing, seven claims arose from the data, within the context of both learning community and knowledge management theory, illustrating processes and structures for knowledge sharing that were thought to contribute towards a knowledge-oriented culture. These claims are:

- Teachers prefer to share their knowledge within a social context.

- Teachers share their knowledge with reflective or critical friends.

- Teachers share their knowledge in an environment of frequent and constructive feedback

- Teachers need quality time to share their knowledge.

- Teachers' credibility influences how knowledge is shared.

- Teachers prefer informal structures when sharing their knowledge.

- Teachers share their knowledge through reflective practice.

The evidence supporting these claims clearly identified how sharing knowledge was deemed critical to teachers' professional learning and how structures and processes that constrain the sharing of knowledge set up barriers that contributed to organisation-wide incoherence and disconnection.

\section{Summary of knowledge sharing findings}

Teachers will share their knowledge, that is, they will share what they believe in, and what they have experienced and what they value, when structures are in place that promotes social interaction. Textual references in this study were abundant and over eighty instances, well distributed across the eighteen stories, could be cited illustrating that sharing teachers' knowledge within a socially constructed environment was a significant determinant in getting "highly personal knowledge out into the open" (Gurteen 1999: online).

That teachers in this study preferred to share their knowledge within a social milieu was evident by the persistent manner and various structures in which teachers strove to present their ideas to their colleagues. All participants in this study indicated that being able to talk, demonstrate, discuss, do, and show their ideas were preferred knowledge sharing processes. They mutually affirmed each other's ideas through the richness of sharing within groups and, when they were 
passionate about what they had learnt, they were determined in their attempts to find social opportunities to share their ideas. They demonstrated their keenness to compare their perspectives and to share ideas across their work units. They were not adverse to collaborative partnerships across their work units but consistently identified barriers such as time, trust, perceived lack of credibility and groupthink that flawed the enactment of such partnerships.

Because sharing knowledge was equated to exposing your emotions, beliefs and values, teachers in this study chose those people, in the first instance, who were deemed critical friends. Closely aligned with Nonaka and Takeuchi's (1995: 85) comment that "the individual's emotions, feelings, and mental models have to be shared to build mutual trust", the teachers in this study looked to colleagues whom they perceived as competent, forward looking, inspirational, honest and trustworthy. Critical friends became testing grounds for participants to articulate their ideas; to make sense of ideas in a judgement free environment, and to assess the workability of ideas.

Knowledge sharing was not a given but resulted in complex interactions that eventually set up structures and processes in which knowledge sharing occurred freely and continuously. Hence, mutually affirming knowledge sharing environments were those structures in which teachers felt psychologically safe, thus confirming the study by Bryk et al (1998) that knowledge, to be truly transformative, needs to be shared within a social setting where dialogue, debate, and discussions are engaged within a groupthink-free environment (Schon 1983). If trust is a core characteristic of a knowledge-oriented culture, groupthink is its antithesis.

Feedback was cited, in one form or another, as the one process that gave shape to participants' ideas and that developed their confidence to continue to openly share their knowledge. Through knowledge sharing opportunities where feedback was immediate, teachers could adjust their practices, clarify their orientation to their role and consequently gain confidence that the members of their learning community perceived their ideas as valuable. As indicated by Todd (2001: 2), if a school is focussed on building its organisational knowledge, it will start first with valuing its teachers' expertises, in open and planned ways. It would be a conversational community characterised by teachers' willingness to:

listen to a range of viewpoints, openly encouraging ...[others] to share their ideas without threat or judgement; acknowledging and profiling the rich expertises, knowledges, experiences and insights held by people in the school - when there is visible, open valuing of knowledge, people are more willing to share.

From the learning community perspective, processes that encourage continuous and immediate feedback ensure that greater and easier access to knowledge cycles throughout the community, giving greater clarity to the community's goals and objectives. Senge (1990), in describing the immediacy and importance of feedback in a learning community, is aligned with Wertheim (1998: online) who states that: 
Feedback taps basic human needs to improve, to compete, to be accurate; people want to be competent. Feedback can be reinforcing; if given properly, feedback is almost always appreciated and motivates people to improve. But for many people, daily work is like bowling with a curtain placed between them and the pins; they receive little information.

When feedback is viewed as genuine, it fosters commitment to the knowledgeoriented culture. Participants in this study who received genuine feedback felt comfortable about sharing their ideas in the knowledge that criticism equated to support and encouragement. Certainly ad hoc or spur of the moment feedback was received favourably, but as this study illustrated, a purposeful and considered process of feedback gave more guarantee that new ideas were on the mark. Such strategic feedback assisted teachers in discarding ideas that were not working and in sharing new knowledge, confidently and competently. Genuine and positive feedback were strongly aligned with credibility and, as this study illustrated, credibility gave the participants confidence to willingly share their ideas. Where participants did not feel credible, an unwillingness to freely share their knowledge across the learning community prevailed.

Interestingly, being credible influenced how teachers measured their self-worth and their confidence in being enabled to share their knowledge. In this study, credibility was linked to not only expertise, but also position in the school. The perception that position equalled credibility undermined a sense of empowerment for classroom teachers in that without position, they felt they had no voice and hence no right to contribute their ideas. They saw themselves as receivers of knowledge and not producers. For teachers to share their knowledge and to be active contributors in a knowledge-oriented culture, they need to be openly, honestly and genuinely recognised as valued and credible members of their community.

Credibility, strategic feedback loops, knowledge sharing opportunities that were embedded into the teachers' work day, time for reflection and evaluation, and social structures that were designed by the teachers contributed to teachers' willingness to create and share their knowledge, to risk-take, to trial and adapt ideas, and to continue to learn. Teachers were less favourable to structures and processes that were mandated, supporting Stacey's observation that any precise descriptions of how teachers will share their knowledge serve only as "invitations for people to stop thinking" (Fullan 1999: 68).

Wiesbord points out, "The quickest way to increase dignity, meaning and community in a work place is to involve people in redesigning their work" (Blanchard 1997: 5). In this study, the teachers were creative in designing knowledge sharing structures that enabled them to share their knowledge during their work day, in social and informal structures that were psychologically safe, and affirming of their self-worth. To a small measure, they had some success and control over designing their knowledge sharing structures; structures that lifted their confidence, facilitated the processes of connection and coherency making, and gave them a voice. Because new ideas can be of a very specific nature, 
freedom to choose the appropriate structure for knowledge sharing was important. Teachers were firm in their preferences for informal smaller knowledge-sharing structures in which a sense of spontaneity and more or less resistance to supervision and interference prevailed.

Structures that were designed by teachers were strongly supported as effective knowledge-sharing environments. They were psychologically safe, flexible in size and purpose, and venue and included a mix of formal (mandated meetings, presentations) and informal (such as the ripple effect and water cooler talks) processes with an emphasis on relevancy and interest.

\section{Summary}

A knowledge-oriented culture will develop if certain conditions are considered in the development of the structures and processes for effective knowledge creation, knowledge sharing and knowledge use across teachers' work units. Knowledge sharing takes place best in an environment in which teachers feel supported physically, emotionally, spiritually and socially and in which knowledge sharing activities are strongly connected to teachers' moral purpose. Socially constructed knowledge sharing activities give teachers the opportunity to engage in critical debate about what matters, to discard redundant ideas, to test their assumptions, and to articulate their "experiences, opinions, insights, hunches, intuition, values and action" (Polanyi 1967) in the pursuit of sense-making.

The best conditions for knowledge sharing, as defined by this study, occur when there is rich social interaction with colleagues. These social interactions rely on structures and processes designed by the teachers that promote frequent and constructive feedback, embed quality time for dialogue and critical debate within the work day, foster an environment where trust is high and groupthink diminished, encourage reflective practice, and actively acknowledge the value of teacher's knowledge. Knowledge sharing was considered by teachers in this study as central in making sense of their work environment. 


\section{PART C What teachers want - what teacher librarians can do}

Teachers bring to their teaching community the full range of human emotion. Thus in building a knowledge-oriented culture, structures that develop and enrich teachers' self-esteem and confidence, and processes that encourage risk-taking, innovative practice, evidence-based practice and conversation open up the knowledge buried in teachers' minds, facilitating the emergence of a knowledge-sharing environment. Teachers who are encouraged and supported in engaging in shared professional learning, and shared evidence-based practice within the context of their own work, deepen their knowledge of self and develop better understanding of their relationships with their colleagues as well as hone their own understanding of their values and of their purpose (Day \& Sachs 2004). For teacher librarians in a knowledge-oriented culture, a shift in the focus from information management to knowledge management means developing a clearer, more strategic understanding of the central role of knowledge in developing a connected and coherence-making school. It extends teacher librarians beyond their roles in information management and student learning and encompasses teachers' professional learning (Southon \& Todd 2000) in the development of organisational fusion, as Daft and Lengel explain:

organisational fusion needs the leadership and enthusiasm of
participants to transform the larger system. Fusion is
accomplished through conversation across traditional
boundaries that meet people's yearning to be a part of
something greater than themselves... to create a shared future
together ... to take action that serves others and the
organisation (1998: 235).

Teacher librarians can facilitate this organisational fusion through their skills in systems thinking, connecting and making coherent teachers' knowledge across the community, nurturing relationships across the school, designing structures and facilitating processes by which teachers can create, share and use their knowledge. This will require empathetic and sensitive valuing of their colleagues' knowledge, as well as their own. It will require teacher librarians to see themselves and their colleagues as credible and significant members of their teaching community who have much to contribute to the school's knowledge reservoir (Handy 1995). And herein lies the challenge.

By designing structures and carefully planning processes that connect teachers' knowledge across the school to minimise the impact of the inevitable knowledge silos that work against coherence making, teacher librarians can better develop strategies to capture and preserve teachers' knowledge, focussing on communities of communication in the deepest sense of the word. These are communities where knowledge creation and knowledge sharing are encouraged, and supported. These are communities where structures and processes are 
critically analysed to ensure that teachers' knowledge is transformed from the tacit to the explicit dimension, shared in diverse yet connected ways so that all teachers in the community understand, feel comfortable with, and can adopt ideas as they shift and refine their mental models.

Teacher librarians, in shifting their mental models of their roles to one where knowledge management and learning community theories inform their practice, are understanding of their colleagues preferred environments for knowledge creation and knowledge sharing, and, as a consequence, demonstrate their readiness to learn from their colleagues as well.

\section{A starting point}

In designing knowledge creation and knowledge sharing structures and processes, conversations focussed on:

1. how the school will capture and use teachers' knowledge,

2. how the school will build and sustain a connected and coherence making community, and

3. how the school will continue to learn whilst at the same time capture and share, use and refresh the community's knowledge

will need to occur. Teacher librarians can help to steer this direction towards a knowledge-oriented culture through their pedagogy based on constructivist and participatory learning. They can:

- demonstrate that they value their teachers' knowledge;

- ask critical questions of knowledge creation, knowledge sharing and knowledge use in their teachers' learning community;

- be aware of the paucity of time as a significant deterrent to effective knowledge creation and knowledge sharing and knowledge use;

- because of this paucity, be empathetic to, and understand, teachers who prefer to remain with the strategies they have, rather than be innovative and risk-taking;

- design and establish professional learning structures that are embedded within the work day;

- offer professional advice on establishing the structures and processes that encourage teachers to step outside their year level group or discipline, cross boundaries of responsibilities, trial and observe new ideas and engage in deep conversations of practice to enable the development of a coherent teachers' learning community. 
- design structures that lead to purposeful and constructive critical dialogue, for example, or promote professional reading across the work units, or encourage professional writing about their daily work and its implications in the broader social, cultural, and political contexts (Cochran-Smith \& Lytle 2003: 7). 


\section{References}

Blanchard, K. (1997). Mission possible: Becoming a world-class organisation while there's still time. NY: McGraw-Hill

Bryk, A., Sebring, P., Kerbow, D., Rollow, S., \& Easton, J. (1998). Charting Chicago school reform. Boulder, CO.: Westview Press.

Calvert, G., Mobley, S. \& Marshall, L. (1994). Grasping the learning organisation. Training, 48(6), pp. 38-43.

Cochran-Smith, M. \& Lytle, S. (1999). Relationships of knowledge and practice: Teacher learning in communities. In Iran-Nejad, A. \& Pearson, C. (Eds) Review of Research in Education, 24(2), 251-307.

Cochran-Smith, M. \& Lytle, S. (2003). Teacher learning communities. In J. W. Guthrie (ed.), Encyclopedia of Education (2nd ed.). NY: Macmillan.

Daft, R. \& Lengel, R. (1998). Fusion leadership. San Francisco: Berrett-Koehler.

Davenport, T. \& Prusak, L. (1998). Working knowledge: How organisations manage what they know. Harvard, CT.: Harvard Business School Press.

Day, C. \& Sachs, J. (2004). Professionalism, performativity, and empowerment: Discourses in the politics, policies and purposes of continuing professional development. Available http://mcgraw-hill.co.uk/openup/chapters/0335209742.pdf Accessed 11/03/05

Denning, S. (2002). Conversations with Stephen Denning. Available www.kwork.org/Stars/denning.html Accessed 20/12/03

Dey, I. (1993). Creating categories. Qualitative data analysis. London: Routledge.

Fankhauser, R. (1999). Intranets: Supporting schools as learning communities. Paper presented at ISIS '99 Online Conference, July, Wagga Wagga, NSW. Charles Sturt University. Available http://www.csu.edu.au/research/cstl/isis/participants/papers/EFankhauser.html Accessed 9/08/99

Foskett, A. (1982). The subject approach to information. Hamden, CT: The Shoe String Press.

Fullan, M. (1999). Change forces: The sequel. London: Falmer Press.

Furlong, G. (2001). Knowledge management and the competitive edge. Available www.gre.ac.uk/schools/business/Dissertation/ Accessed 02/12/04.

Groundwater-Smith, S. \& Sachs, J. (2002). The activist professional and the reinstatement of trust. Cambridge Journal of Education, 32(3), pp. 341-358.

Gurteen, D. (1999). Creating a knowledge sharing culture. Available http://www.gurteen.com/gurteen/gurteen.nsf/0/FD35AF9606901C42802567C70068C

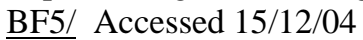

Handy, C. (1995). The gods of management. London: Arrow 
Hargreaves, D. (1999). The knowledge creating school. In British Journal of Educational Studies, 47(2), pp. 122 - 144.

Haeusler, M. (2002). A professional learning community: Is this the organisational network of the future? Available

www.cybertext.net.au/tct2002/disc_papers/organisation/haeusler.htm

Accessed 20/12/03.

Langford, L. (1999). Is your school a dancing school? The teacher librarian as dance partner. In Bytes, books and bollards by the bay: Information management for the third millennium. Richmond: SLAV. 204-210.

Leonard-Barton, D. (1995). Wellsprings of knowledge. Boston, MA.: Harvard Business School Press.

Lincoln, Y., \& Guba, E. (1985). Naturalistic inquiry. Newbury Park, CA.: Sage.

Louis, K. \& Kruse, S. (Eds.). (1995). Professionalism and community: Perspectives on reforming urban schools. Thousand Oaks, CA: Corwin Press.

Molholm, K. (2003). Is what's past, prologue? Available http://www.nfais.org/publications/mc lecture_2003.htm\#_edn17 Accessed 10/01/04

Newmann, F. \& Wehlage, G. (1995). Successful school restructuring. Madison, WI: Center on Organisation \& Restructuring of Schools.

Nonaka, I. \& Takeuchi, H. (1995). The knowledge-creating company. Oxford: Oxford University Press.

Patton, M. (1990). Qualitative evaluation and research methods. (2nd ed.). Newbury Park, CA.: Sage.

Polanyi, M. (1967). The tacit dimension. London: Routledge \& Kegan Paul.

Rosenholtz, S. (1989). Teachers' workplace: The social organisation of schools. New York: Longman.

Santosus, M. (2001) It takes a community. Available www.cio.com/research/knowledge/edit/cops.html Accessed 22/01/04.

Sbarcea, K. (2000). Despatches from the trenches. Presentation at KM in the trenches: Making it work for you. Sydney June 20-21.

Schön, D. (1983). Educating the reflective practitioner: Towards a new design for teaching and learning in the profession. San Francisco: Jossey-Bass.

Senge, P. (1990). The fifth discipline: The art \& practice of the learning organization. NY:

Currency Doubleday.

Sergiovanni, T. (1994). Building community in schools. San Francisco: Jossey-Bass.

Sinclair, D. \& Hardie, N (2000). Knowledge management Part 1: The basics. Available http://www1.cmis.csiro.au/statline/2000/Apr2000.htm Accessed 30/01/05.

Southon, G. \& Todd, R. (2000). Knowledge management: Key to partnerships, learning outcomes, and resourcing a learning community. Proceedings of the Fourth International Forum 
on Research in School Librarianship. Do you read me? $29^{\text {th }}$ Annual IASL Conference. August, Malmo, Sweden. pp. 67-77.

Stoll, L. \& Fink, D. (1996). Changing our schools: Linking school effectiveness with school improvement. Buckingham: Open University Press.

Svetvilas, C. (2001). The human factor: Intellectual capital guru Nick Bontis discusses KM's missing link. Available http://www.intelligentkm.com/feature/010723/feat1.shtml Accessed 15/12/04.

Todd, R. (1999b). Knowledge management 2: Processes and practices. Scan, 18(2), pp. 39-43.

Todd, R. (2001). Building a knowledge-sharing culture. Connections, 37, pp. 1-3.

Wertheim, E. (1998). The importance of effective communication. Available http://web.cba.neu.edu/ ewertheim/interper/commun.htm Accessed 12/02/05

Wiig, K. (1993). Knowledge management foundations. Arlington,TX.: Schema Press.

Williamson, K. (Ed.). (2000). Research methods for students and professionals: Information management and systems. Charles Sturt University, Wagga Wagga, NSW: CIS.

Yin, R. (1994). Case study research: Design and methods. (2 $2^{\text {nd }}$ edn.). Thousand Oaks, CA.: Sage.

\section{Author's note}

Linda C Langford, a Canadian-born Australian, is a PHD student at Charles Sturt University, Wagga Wagga and an Information Literacy Teacher at The King's School, Sydney. She has presented at National and International conferences over the past 15 years and has published a number of journal and book articles with a focus on learning communities and information literacy.

One of her more notable speaking experiences was being sung to 'a capella' by a chorus of South Africans just prior to her keynote address in Capetown. 


\section{Appendix One}

\section{Teachers in a learning community}

Although the literature reveals numerous lists of qualities or characteristics of learning communities by which to gauge viability, or to design the infrastructure for its members to converse, reflect, to take risks, and to appreciate new ideas, such lists, specifically relating to teachers' learning communities, are rare. Starratt (quoted in Retallick 1999: 111) warns that undertaking the task of building a learning community in a school will be unique, but 'will manifest some common, core processes'. However, for this study, it was Hord's (1997) review of the literature on professional learning communities that establishes a set of core or common processes that identify the importance of knowledge production within a teachers' learning community. They are:

- supportive and shared leadership,

- shared decision-making,

- collective creativity,

- adaptive and innovative learning,

- commitment to shared values and vision articulating to clearly defined purposes,

- $\quad$ supportive conditions:

- Structural environment - time to talk, small size, interdependence of teaching roles, communication structures, teacher empowerment, staff selection of teachers and administrators, availability of resources, schedules and structures that reduce isolation, and policies providing greater autonomy, fostering communication, collaboration, and staff development,

- People environment - feedback, shared ongoing vision, respect, trust, continuous enabling learning thus increasing teacher capacity, supportive leadership, intense socialization processes, continuous critical inquiry, caring,

- shared personal practice through peer review, accepting challenging tasks, risk taking, debate, praise, empathy, mutual respect, trustworthiness,

- and, from Senge (1990), systems thinking - making coherent a knowledgesharing culture that connects the community's knowledge-of-practice, knowledge-for-practice and knowledge-in- practice. 
Reproduced with permission of the copyright owner. Further reproduction prohibited without permission. 